07,01

\title{
Влияние структурного состояния и оксидного покрытия на механостабильность титана ВТ1-0 при его циклическом нагружении
}

\author{
(C) В.И. Бетехтин ${ }^{1}$, А.Г. Кадомцев ${ }^{1}$, М.В. Нарыкова ${ }^{1}$, О.В. Амосова ${ }^{1}$, Ю.Р. Колобов ${ }^{2}$, \\ V. Sklenicka ${ }^{3}$, J. Dvorak ${ }^{3}$ \\ ${ }^{1}$ Физико-технический институт им. А.Ф. Иофрфе, \\ Санкт-Петербург, Россия \\ ${ }^{2}$ Белгородский государственный национальный исследовательский университет, \\ Белгород, Россия \\ ${ }^{3}$ Institute of Physics of Materials, Academy of Sciences of the Czech Republic, \\ Brno, Czech Republic \\ E-mail: Maria.Narykova@mail.ioffe.ru \\ Поступила в Редакцию 12 мая 2021 г. \\ В окончательной редакции 12 мая 2021 г. \\ Принята к публикации 13 мая 2021 г.
}

Установлено, что усталостные свойства субмикрокристаллического титана существенно выше, чем для его крупнозернистого состояния. Нанесение оксидного покрытия ведет к небольшому повышению этих свойств для титана как с субмикрокристаллической, так и с крупнозернистой структурой. Анализируются некоторые особенности усталостного разрушения субмикрокристаллического и крупнозернистого титана.

Ключевые слова: субмикрокристаллический и крупнозернистый титан, ВТ1-0, усталость, микродуговое оксидирование.

DOI: 10.21883/FTT.2021.11.51595.109

\section{1. Введение}

Титан в силу особенностей своих свойств (низкая плотность, коррозиестойкость, хорошая биосовместимость) является основным конструкционным материалом в медицинской области $[1,2]$. С учетом этого получение высокопрочного титана и изучение влияния на эволюцию и стабильность его прочностных характеристик в условиях длительного циклического нагружения весьма актуально. Не менее важным представляется оценка влияния на прочность титана оксидного покрытия, которое улучшает биосовместимость титановых имплантатов с организмом человека [1]. В настоящее время для получения высокопрочного титана с субмикрокристаллической (СМК) структурой используют обычно методы интенсивной пластической деформации (ИПД) [3-5]. Однако, сформированная при ИПД структура нестабильна $[5,6]$, и ее эволюция в процессе длительного нагружения может привести к снижению прочностных свойств $[7,8]$. Важна также оценка вклада в эти свойства поверхностного покрытия.

С учетом всего вышесказанного основной целью настоящей работы являлось изучение влияния сложного циклического нагружения на величину и механостабильность прочностных свойств титана с СМК и крупнозернистой (КЗ) структурой и оценка вклада в эволюцию этих свойств оксидного покрытия. При анализе особенностей усталостного разрушения учитывались полученные ранее результаты [9-13].

\section{2. Материалы и методы}

Объектом исследований в настоящей работе является титан технической чистоты (сплав ВТ1-0) в СМК- и КЗ-состояниях. СМК-состояние было получено по разработанному авторами [2] режиму механико-термической обработки с использованием продольной и поперечно-винтовой прокаток, позволяющих получать прутки СМК-титана диаметром 4-10 $\mathrm{mm}$. В настоящей работе использовались прутки титанового сплава ВТ1-0 диаметром $8 \mathrm{~mm}$, которые подвергали финишному отжигу при температуре $623 \mathrm{~K}$ в течении 3 часов для снятия внутренних напряжений первого рода. После указанной обработки сплав характеризуется однородной зеренносубзеренной структурой со средним размером структурных элементов порядка $190 \mathrm{~nm}$. Однородная рекристаллизованная структура ВТ1-0 (КЗ-состояние) была получена из СМК-структуры выдержкой при $T=823 \mathrm{~K}$ в течении одного h. Средний размер зерна для КЗ-состояния составляет $2.35 \mu \mathrm{m}$.

Для проведения исследования усталостных свойств из стержней изготавливались образцы с толщиной рабочей области $1 \mathrm{~mm}$ и шириной $3 \mathrm{~mm}$. На поверхность образцов как в СМК-состоянии, так и в КЗ-состоянии методом микродугового оксидирования (МДО) было нанесено покрытие толщиной 8-10 $\mu \mathrm{m}$. В состав покрытия входят оксиды кремния (не менее $30 \mathrm{~mol} . \%$ ), оксиды кальция (не менее 2.5 mol.\%), оксиды фосфора (не более $6 \mathrm{~mol} . \%$ ), оксиды натрия (от 0.5 до $3.0 \mathrm{~mol} \%$ ), а также оксиды титана (не менее $20 \mathrm{~mol} . \%$ ). 
Такие покрытия, обладающие высокой макропористостью и хорошей износостойкостью, с успехом в последнее время используются в протезировании и стоматологии [1]. Протезы из титана с биосовместимым покрытием могут находиться в теле человека много лет. На протяжении всего этого периода они испытывают циклические нагрузки. Поэтому изучение усталостной долговечности титана, в том числе с нанесенным покрытием, является одной из актуальных задач в биомедицине.

Для исследования усталостных характеристик при растягивающей нагрузке для образцов титанового сплава ВТ1-0 использовалась испытательная машина, оснащенная электромагнитным приводом, Instron Electropulse E3000 в режиме нагружения с частотой $50 \mathrm{~Hz}$ при комнатной температуре. Испытания проводили по схеме нагружения растяжением в симметричном пилообразном цикле в области нагружения $0.9 \sigma_{\max }-0.2 \sigma_{\max }$. Предельное количество циклов для исследованных образцов составляло $2 \cdot 10^{6}$, а величина нагрузки, при которой не происходило разрушения при этом числе циклов, служила характеристикой условного предела выносливости.

Одна из причин нестабильности СМК-титана, способствующая снижению его прочностных свойств при длительном нагружении, может быть связана с образованием при ИПД нанопористости. Действительно, в [9-16] показано, что при разных методах ИПД в металлах и сплавах образуются поры размером $\sim 10-100 \mathrm{~nm}$. Наличие таких нанопор практически не влияет на характеристики прочности при „кратковременном“ нагружении (предел прочности, текучести, микротвердость), но в условиях длительного нагружения в режиме ползучести, усталости эти нанопоры могут являться „очагами“ развития микроразрушения, снижающими высокие механические свойства и механостабильность титана [7].

С учетом этого обстоятельства в работе методом малоуглового рентгеновского рассеяния (МРP), модернизированным авторами $[9,10,17]$, определяли параметры нанопор и оценивали их объем. Помимо этого, прецизионным методом тройного гидростатического взвешивания (погрешность не превышала $10^{-4}$ ) измерялась плотность титана до и после ИПД. Плотность и ее изменение (дефект плотности) позволяли оценить суммарный объем повреждаемости, вносимый ИПД. Сопоставление дефекта плотности и объема выявленных методом МРР нанопор позволяет вычислить вклад последних в общую повреждаемость за счет ИПД.

Методом электронной сканирующей микроскопии в работе были получены и проанализированы данные по поверхности разрушения СМК- и КЗ-образцов титана после их усталостного испытания при $2 \cdot 10^{6}$ циклах и долома.

\section{3. Экспериментальные результаты и их анализ}

Прежде всего рассмотрим и проанализируем результаты циклических испытаний для образцов СМК- и

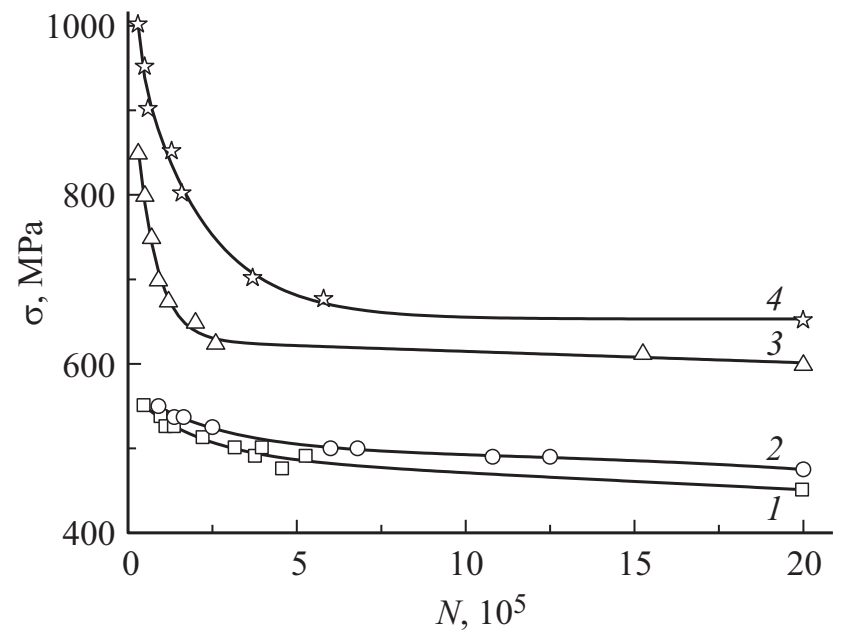

Рис. 1. Кривые Веллера титана ВТ1-0 в различных состояниях: 1 - КЗ-состояние, $2-$ КЗ-состояние + МДО-покрытие, 3 - СМК-состояние, 4 - СМК-состояние + МДО-покрытие.

КЗ-титана. На рис. 1 для этих образцов показана зависимость величины приложенных нагрузок (в области $\left.0.9 \sigma_{\max }-0.2 \sigma_{\max }\right)$ от числа циклов (кривые Веллера). Условный предел выносливости (УПВ) определялся по кривой, уравнение которой подбиралось по экспериментальным точкам методом наименьших квадратов. В результате установлено, что величина условного предела выносливости для титана с СМК-структурой $611 \pm 8 \mathrm{MPa}$, а для титана с КЗ-структурой $450 \pm 8 \mathrm{MPa}$. Таким образом, при $2 \cdot 10^{6}$ циклах нагружения УПВ титана с СМК-структурой в 1.4 больше, чем для КЗ-аналога. Показательно, что кривые усталости для СМК-титана проходят существенно выше, чем для КЗ-состояния во всем интервале исследованных нагрузок.

Однако, как видно из рис. 1, для СМК-титана спад усталостной кривой с ростом числа циклов происходит более резко, чем для КЗ-титана. Это приводит к тому, что в процессе циклического нагружения „эффективность“ СМК-состояния уменьшается: при $2 \cdot 10^{5}$ циклах УПВ СМК-титана был в 1.6 раз больше, чем для КЗ-титана, а при $2 \cdot 10^{6}$ циклах это отношение уменьшилось до 1.4 .

Падение „эффективности“ СМК-структуры может быть связано с развитием повреждаемости (в основном, нанопористости) в СМК-титане после ИПД.

Действительно, результаты исследованных МРР образцов СМК- и КЗ-титана до их усталостных испытаний показали, что в СМК-титане после ИПД образуются нанопоры размером $\sim 20 \mathrm{~nm}$.

На рис. 2 приведен второй инвариант рентгеновского рассеяния до и после воздействия на образец гидростатического давления $1 \mathrm{GPa}$. Как показано в $[9,10,17]$, воздействие такого давления ведет к залечиванию несплошностей. 


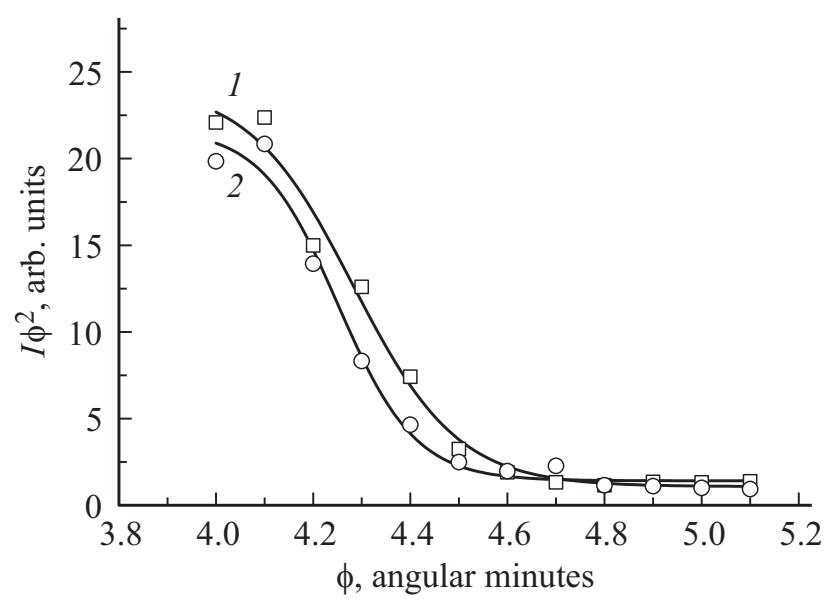

Рис. 2. Кривые втоных инвариантов рентгеновского рассеяния для ВТ1-0: 1 - СМК-состояние, 2 - СМК-состояние после приложения гидростатического давления $1 \mathrm{GPa}$.

Это позволяет выявить долю малоуглового рассеяния, обусловленного наличием несплошностей. В предположении сферической формы нанопор были оценены согласно $[17,18]$ их средние размеры и концентрации, а также объемная доля. Оказалось, что для СМК-титана объемная доля составляет $\sim 4 \cdot 10^{-4}$.

Аналогичные исследования, проведенные для титана в КЗ-состоянии, практически не выявили наличия нанопористости. Очевидно, что высокотемпературный отжиг, который использовался для получения КЗ-титана, привел к существенному залечиванию нанопор.

Было проведено также измерение плотности КЗ- и СМК-титана до их испытания в условиях циклического нагружения. Оказалось, что плотность КЗ-титана 4.4983, а СМК-титана - $4.4963 \mathrm{~g} / \mathrm{cm}^{3}$, т.е. заметно меньше. Дефект плотности при сравнении СМК-титана, содержащего нанопоры, и беспористого КЗ-титана составил $4.4 \cdot 10^{-4}$. Это значение достаточно хорошо согласуется с объемом нанопор, выявленных в СМК-титане методом МРР. Последнее свидетельствует о том, что образовавшееся в СМК-титане при его получении методом ИПД разуплотнение обусловлено, в основном, образованием нанопористости.

Таким образом, небольшое снижение условного предела выносливости в процессе усталостного нагружения обусловлено, очевидно, эволюцией нанопористости, которая образовалась еще в процессе приготовления высокопрочной СМК-структуры. Тем не менее, механостабильность СМК-титана остается достаточно высокой, и его условный предел выносливости после $2 \cdot 10^{6}$ циклов, как уже отмечалось, существенно выше, чем для КЗ-состояния.

О влиянии нанопористости, образовавшейся в СМКтитане в процессе ИПД, на условный предел выносливости свидетельствуют также данные, полученные авторами ранее [12]. В интервале $10^{4}-10^{7}$ циклов были получены кривые Веллера для двух партий (,А“ и „В“)
СМК-титана, изготовленных в том же, что и в настоящей работе, режиме. Структурные исследования показали, что размер зерен $(\sim 190 \mathrm{~nm})$ и их разориентация в партиях „А“ и „В“ одинаковы. Однако, условный предел выносливости образцов в партии „А“ оказался 252 , а в партии „В“ $-212 \mathrm{MPa}$. При этом уровень нанопористости, образовавшейся после ИПД, в партии „В“ оказался выше, чем в партии „А“.

Отметим, что более высокая нанопористость СМКтитана партии „В“ обусловлена, очевидно, более высоким (чем в партии „А“) содержанием неметаллических включений типа карбидов. В процессе больших ИПД эти включения способствуют образованию повышенной концентрации вакансий, коагуляция которых ведет к образованию нанопор [10] и снижению УПВ и долговечности при циклическом нагружении.

В связи с этим важно отметить, что при длительном нагружении и в условиях высокотемпературной ползучести ряда СМК-металлов и сплавов, приготовленных разными методами ИПД, именно эволюция ,исходных“ нанопор ведет к снижению их долговечности (механостабильности). Термобарическое залечивание образовавшихся в процессе ИПД нанопор позволяет повысить долговечность (ресурс эксплуатации) высокопрочных СМК-металлов и сплавов $[7,8]$.

Совокупность полученных и рассмотренных выше данных позволяет полагать, что механостабильность имплантатов, изготовленных из СМК-титана, может быть также повышена за счет разработки оптимальных режимов залечивания образовавшихся в них в процессе ИПД повреждений типа напор.

Рассмотрим и проанализируем теперь полученные в работе данные о усталостных характеристиках СМК- и КЗ-титана с нанесенными на их поверхность оксидными покрытиями (рис. 1). Эти покрытия имеют разветвлен-

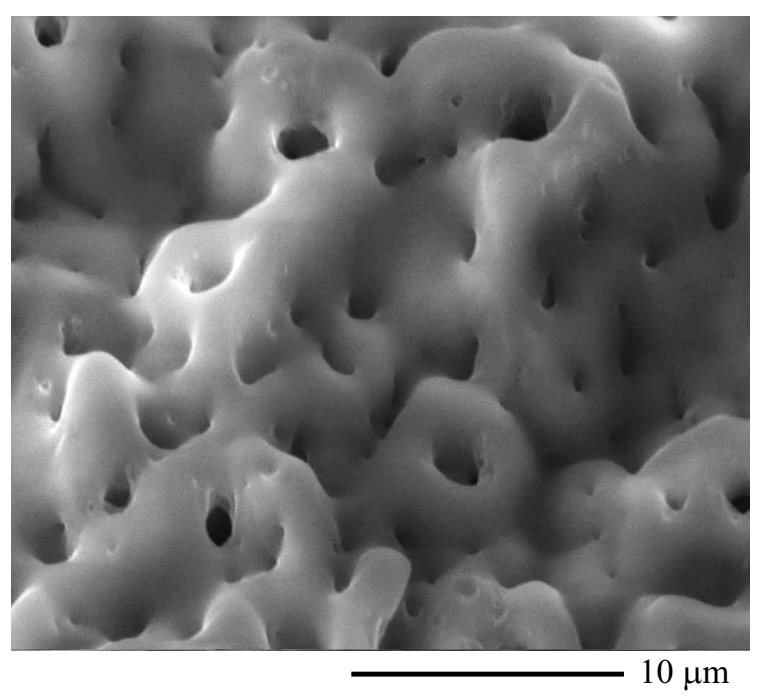

Рис. 3. Изображение морфологии поверхности МДО-покрытий на сплаве ВТ1-0. Растровая электронная микроскопия при увеличении 100000 под углом $45^{\circ}$. 
ную пористую поверхность (рис. 3), которая, как отмечалось, способствует повышению биосовместимости имплантатов с организмом человека. Помимо этого, как следует из полученных данных (рис. 1), оксидные покрытия ведут еще и к небольшому повышению усталостных свойств (кривые Веллера) во всем исследованном диапазоне циклических нагрузок. Этот упрочняющий эффект покрытий имеет место как для СМК-, так и для К3-титана. Однако спад усталостной кривой с ростом числа циклов для СМК-образцов с покрытиями происходит более резко, чем для КЗ-образцов с покрытиями. Подобный эффект наблюдается и для СМК- и КЗ-титана без покрытий, но в случае покрытий он даже более сильный. Так, для СМК-титана с покрытиями при $2 \cdot 10^{5}$ циклах УПВ в 1.8 раз выше, чем для КЗ-титана. При $2 \cdot 10^{6}$ циклах это отношение составляет 1.4. Иными словами, при циклических испытаниях СМК-титана с покрытиями тенденция понижения условного предела выносливости с ростом числа циклов нагружения даже несколько более высокая, чем для СМК-титана без покрытий.

Представляется, что основной причиной снижения „эффективности“ СМК-титана с покрытиями и без покрытий является эволюция при циклическом нагружении „исходной“ нанопористости. В случае СМК-титана с покрытиями имеется, очевидно, еще один фактор, влияющий на ход изменения кривой Веллера. Таким фактором может быть морфология поверхности СМКи КЗ-титана, на которую наносится оксидное покрытие. Известно, что при циклическом нагружении усиливается роль поверхностных дефектов [19-21] и особенностей дислокационно-дисклинационной структуры тонких $(\sim 10-30 \mu \mathrm{m})$ приповерхностных слоев [22-24]. Возможно, что отжиг при достаточно высокой температуре, который проводился для перевода СМК-структуры в КЗ-состояние, привел к менее дефектной приповерхностной структуре КЗ-титана по сравнению с СМК-аналогом. Это обстоятельство увеличивает соотношение условного предела выносливости при $10^{5}$ циклах нагружении СМК- и КЗ-титана с покрытиями по сравнению с этими образцами без покрытий.

Рассмотрим теперь некоторые результаты электронномикроскопических исследований, которые проводились при изучении поверхности разрыва образцов после их циклического нагружения и доведения до разрыва при активном нагружении.

Основное внимание при этих исследованиях уделялось влиянию покрытий и их связи с усталостным разрушением. Прежде всего отметим, что полученные на поверхности излома данные свидетельствуют об отсутствии отслаивания покрытий при разрушении образцов (рис. 4). Отслаивание наблюдается только в области разрушения из-за большой локальной деформации образцов при их доломе (рис. 5). Это говорит о хорошей адгезионной связи покрытий с поверхностью образцов титана. В поверхностных образцах титана покрытия оказывают упрочняющий эффект и противодействие пластической

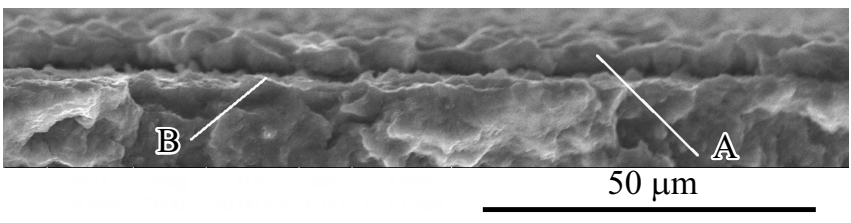

Рис. 4. Изображение поверхности излома образца ВТ1-0 с МДО-покрытием в обрасти усталостного разрушения; А МДО-порытие, В - граница раздела металл-покрытие.

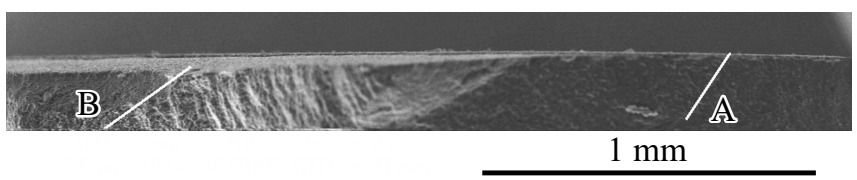

Рис. 5. Изображение поверхности излома образца ВТ1-0 с МДО-покрытием в обрасти усталостного разрушения после долома; А - МДО-порытие отслоилось, В - область отслаивания МДО-покрытия.

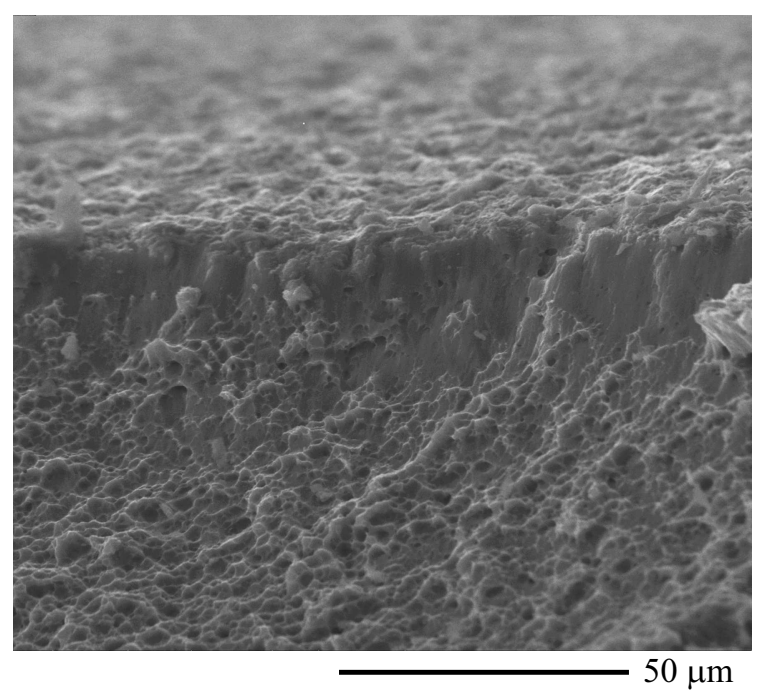

Рис. 6. Изображение поверхности излома в приповерхностной области образца ВТ1-0 с покрытием после усталостных испытаний в области долома.

деформации. Об этом свидетельствует изменение направленности формы ямок при усталостном разрушении в приповерхностных слоях: ямки вытянуты не вдоль направления нагрузки, а перпендикулярно поверхности покрытия (рис. 6). (Как известно, ямки вытягиваются вдоль максимальной нагрузки).

Вероятно, что более высокое значение усталостной прочности для образцов с покрытиями связано с их влиянием на залечивание поверхностных и приповерхностных дефектов, которые являются „очагами“ развития разрушения при циклическом нагружении. Нельзя также исключить, что оксидные покрытия могут иметь более высокие механические характеристики, чем СМК- 
и КЗ-титан, и их нанесение способствует повышению усталостных характеристик.

\section{4. Заключение}

Установлено, что условный предел выносливости (УПВ) при $2 \cdot 10^{6}$ циклах нагружения у СМК-титана с покрытиями и без них в 1.4 раза больше, чем у аналогичного КЗ-титана. Оксидные покрытия ведут к небольшому ( 8\%) повышению усталостных характеристик СМКи КЗ-титана во всем интервале изучения циклического нагружения.

Обнаружена тенденция снижения УПВ у СМК-титана при росте числа циклов нагружения. Так для СМК-титана без покрытий УПВ при $\sim 2 \cdot 10^{5}$ циклах был в 1.6 раз больше, чем у КЗ-титана. Структурные исследования показали, что наблюдаемый эффект (снижение отношения УПВ с 1.6 до 1.4) может быть обусловлен эволюцией повреждений (особенно нанопористостью), образовавшихся в процессе ИПД при получении СМК-состояния.

Для СМК-титана с покрытиями этот эффект при $2 \cdot 10^{5}$ циклах нагружения оказывается 1.8 , т.е. еще больше. Анализируется природа упрочняющего влияния оксидных покрытий на долговечность и УПВ при циклическом нагружении СМК- и КЗ-титана.

\section{Благодарности}

Выражаем признательность к.ф.-м.н. И.В. Неласову (Белгородский государственный национальный исследовательский университет, Россия) за ценный вклад при проведении микроскопических исследований.

\section{Финансирование работы}

Исследование выполнено при финансовой поддержке РФФИ и ЧНФ в рамках научного проекта № 19-58-26005.

\section{Конфликт интересов}

Авторы заявляют, что у них нет конфликта интересов.

\section{Список литературы}

[1] N. Huang, P. Yang, Y.X. Leng, J.Y. Chen, H. Sun, J. Wang, G.J. Wang, P.D. Ding, T.F. Xi, Y. Leng. Biomaterials 24, 13, 2177 (2003).

[2] Ю.Р. Колобов. Рос. нанотехнологии 4, 11-12, 69 (2009).

[3] H. Gleiter. Progr. Mater. Sci. 33, 233 (1986).

[4] Р.З. Валиев, Г.В. Александров. Наноструктурные металлы, полученные методами интенсивной пластической деформации. Логос, М. (2002). 272 с.

[5] Р.А. Андриевский, А.М. Глезер. УФН 179, 4, 337 (2009).

[6] Р.А. Андриевский. Успехи химии 83, 4, 365 (2014).

[7] В.И. Бетехтин, А.Г. Кадомцев, М.В. Нарыкова. ФТТ 62, 2 , 267 (2020).
[8] J. Dvorak, V. Sklenicka, V.I. Betekhtin, A.G. Kadomtsev, P. Kral, M. Svoboda. Mater. Sci. Eng. A. 584, 103 (2013).

[9] В.И. Бетехтин, А.Г. Кадомцев, V. Sklenicka, I. Saxl. ФТТ 49, 10, 1787 (2007).

[10] В.И. Бетехтин, V. Sklenicka, Б.К. Кардашев, I. Saxl, А.Г. Кадомцев, М.В. Нарыкова. ФТТ 52, 8, 1517 (2010).

[11] Б.К. Кардашев, В.И. Бетехтин, М.В. Нарыкова, А.Г. Кадомцев, О.В. Амосова. ЖТФ 89, 10, 1563 (2019).

[12] В.И. Бетехтин, Ю.Р. Колобов, V. Sklenicka, А.Г. Кадомцев, М.B. Нарыкова, J. Dvorak, E.В. Голосов, Б.К. Кардашев, И.Н. Кузьменко. ЖТФ 85, 1, 66 (2015).

[13] R. Lapovok, D. Tomus, J. Mang, Y. Estrin, T.C. Lowe. Acta Mater. 57, 2909 (2009)

[14] J. Ribbe, G. Schmitz, D. Gunderov, Y. Estrin, Y. Amouyal, S.V. Divinski. Acta Mater. 61, 5477 (2013).

[15] S.V. Divinski, G. Reglitz, I.S. Golovin, M. Peterlechner, R. Lapovok, Y. Estrin, G. Wilde. Acta Mater. 82, 11 (2015).

[16] X. Sauvage, R. Pippan. Mater. Sci. Eng A 410-411, 345 (2005).

[17] В.И. Бетехтин, А.Г. Кадомцев. ФТТ 47, 5, 801 (2005).

[18] A. Guinier, G. Fournet. Small-Angle Scattering of X-rays, J. Wiley, N.Y. (1955). 268 p.

[19] I.R. Krammer. Fundamental Phenomena Mater. Sci. 4. N.Y. Plenum. Press. 351 (1967).

[20] V.F. Terentyev, S.V. Dobatkin, S.A. Nikulin, V.I. Kopylov, D.V. Prosvirnin, S.O. Rogachev, I.O. Bannykh. Kovove Mater. 49, 65 (2011).

[21] А.Ю. Виноградов, С. Хасимото. Металлы. 1, 51 (2004).

[22] В.И. Бетехтин, В.И. Владимиров, А.И. Петров, А.Г. Кадомцев. Поверхность. Физика, химия, механика 7, 144 (1986).

[23] В.И. Владимиров. Физическая природа разрушения металлов. Металлургия, М. (1984). 280 с.

[24] В.И. Владимиров, А.Е. Романов. Дисклинации в кристаллах. Наука, Л. (1986). 223 с.

Редактор Е.Ю. Флегонтова 